\title{
Note from the Editors
}

The editors of Iranian Studies gratefully acknowledge the generous financial contribution of the Center for Iranian Studies at Columbia University toward the cost of publication of this double-issue of the Journal. We are especially indebted to Professor Ehsan Yarshater, Director of the Columbia Center, for his encouragement, guidance, and financial support of the Journal's activities. The entire field of Iranian Studies is well-served by such an eminent scholar whose unfailing support of scholarly research on Iran is unmatched. 